\title{
Sequential coronary artery endothelial function measurements differ in CAD patients and healthy subjects: a cardiac MRI study
} Sebastian Kelle*1, Allison G Hays ${ }^{2}$, Glenn A Hirsch², Angela Steinberg2, Michael Schär ${ }^{3}$, Robert G Weiss ${ }^{2}$, Gary Gerstenblith ${ }^{2}$ and Matthias Stuber ${ }^{2}$

\author{
Address: ${ }^{1}$ German Heart Institute Berlin, Berlin, Germany, ${ }^{2}$ Johns Hopkins University, Baltimore, MD, USA and ${ }^{3}$ Philips Healthcare, Cleveland, \\ $\mathrm{OH}, \mathrm{USA}$ \\ * Corresponding author
}

from 13th Annual SCMR Scientific Sessions

Phoenix, AZ, USA. 2I-24 January 2010

Published: 21 January 2010

Journal of Cardiovascular Magnetic Resonance 2010, I2(Suppl I):O84 doi:10.1 186/1532-429X-12-SI-O84

This abstract is available from: http://jcmr-online.com/content/I2/SI/O84

(C) 2010 Kelle et al; licensee BioMed Central Ltd.

\section{Introduction}

Sequential studies allowing paired comparisons of artery dimension and blood flow responses to endothelialdependent stresses before and following an acute intervention are often used to assess endothelial function. This paradigm is only valid, however, if the second response does not differ from the first in the absence of an intervention.

\section{Purpose}

We evaluated the validity of this paradigm for coronary arteries using MRI in healthy subjects and in those with coronary disease, using isometric handgrip (IHG) as the endothelial-dependent stressor.

\section{Methods}

Coronary artery cross-sectional area and blood flow were quantified before and during two sequential IHG stresses in twenty healthy adult subjects and 12 CAD patients using a commercial 3.0 Tesla (T) whole-body MR imaging system (Achieva 3.0 T; Philips, Best, NL). The second study was performed after 10 minutes, when hemodynamic parameters had returned to baseline values.

\section{Results}

In healthy adult subjects, baseline, resting values prior to the first and second IHG stresses were similar (1. vs. 2 . area: $10.1 \pm 2.8$ vs. $10.3 \pm 2.4 \mathrm{~mm} 2, \mathrm{p}=0.51$; blood-flow: $63.2 \pm 24.9$ vs. $63.1 \pm 29.4 \mathrm{ml} / \mathrm{min}, \mathrm{p}=0.98)$. In healthy subjects, coronary arteries dilated and blood-flow increased during IHG and the change and absolute values did not differ between the first and second IHG stresses ( 1 . stress vs. 2 . stress \%-area-change: $14.8 . \pm 18.2$ vs. $17.2 \pm$ $13.3 \%, \mathrm{p}=0.53$; \%-blood-flow-change: $48.5 \pm 44.7$ vs. $51.1 \pm 35.5 \%, \mathrm{p}=0.75)$. In CAD patients, however, despite the return of pulse and blood pressure to the preIHG measures, coronary cross-sectional area and blood flow before the second IHG stress did not return to baseline (1. vs. 2. pre-IHG stress area: $14.0 \pm 4.2$ vs. $13.1 \pm 3.8$ $\mathrm{mm} 2, \mathrm{p}=0.01$; blood-flow: $83.9 \pm 37.6$ vs. $69.6 \pm 19.7$ $\mathrm{ml} / \mathrm{min}, \mathrm{p}=0.03$ ). Consequently, the expected changes induced by IHG were significantly attenuated, i.e. the decrease in these parameters observed during the first IHG did not occur during the second (1. vs. 2 . stress \%-areachange: $-6.7 \pm 7.6$ vs. $1.8 \pm 8.2 \%, p=0.01$; $\%$-blood-flowchange: $-9.3 \pm 19.8$ vs. $6.4 \pm 18.8 \%, \mathrm{p}=0.03$ ).

\section{Conclusion}

Although the coronary endothelial response to sequential IHG is similar in healthy adult subjects it significantly differs in CAD patients despite the return of pulse and blood pressure to pre-stress levels. These findings should be considered in future studies examining the impact of interventions designed to alter coronary endothelial function in patients with CAD. 